\title{
Solute release mechanisms from confined sediment cores in stirred benthic chambers and flume flows
}

\author{
M. Huettel ${ }^{1}$, G. Gust ${ }^{2, *}$ \\ ' Zoologisches Institut der Universität Kiel, Marine Ökologie und Systematik, Olshausenstrasse 40, W-2300 Kiel, Germany \\ ${ }^{2}$ University of South Florida, Department of Marine Science, 1407 th Ave. S, St. Petersburg, Florida 33701, USA
}

\begin{abstract}
Interfacial solute fluxes from sediment cores enclosed in stirred chambers were compared with solute fluxes from a reference core inserted in a flume simulating in situ conditions with unidirectional boundary-layer flow. Utilizing Rhodamine-WT dye as conservative solute, and quantifying the hydrodynamic driving forces by hot film anemometry and a highly sensitive wet/wet differential pressure transducer, the pathways of solutes in chamber- and flume-confined cores are identified. The critical parameter limiting confined-core flux techniques is the sediment permeability, with equivalency between experimental techniques and natural, smooth bottoms found for impermeable sediments only, where bottom stress and Schmidt number act as the controlling parameters permitting use of diffusive laws. In contrast, pressure gradients, induced by edge and sidewall effects in cores under unidirectional flow and by circular flow patterns in stirred chambers, being ineffective for impermeable sediments, generate non-negligible advective porewater flows in permeable sediments. For fine sandy sediment ( $\phi=2.2$; permeability $K=15$ Darcy, D), stirred-chamber circular flow enhanced solute release up to 6 -fold over that from the reference core exposed to 2-dimensional flow, with intruding supernatant water reaching up to 8 -fold deeper into the porespace. Consequences of these advective exchange processes include release of anoxic porewater and increased oxygen uptake in permeable cores, with shifts in redox isolines affecting biological and geochemical processes in the sediment. Results suggest that chamber fluxes are both site- and device-dependent and cannot be automatically equated with in situ fluxes.
\end{abstract}

\section{INTRODUCTION}

Solute fluxes at the sediment-water interface occur along several pathways: molecular diffusion based on concentration gradients (Berner 1976); bioturbation by benthic organisms (Rhoads et al. 1977, Gust \& Harrison 1981, Aller \& Yingst 1985, Huettel 1990); advective replacement of pore fluid by supernatant waters driven by waves, tides, and pressure gradients related to sediment microtopography (Webb \& Theodor 1968. 1972, Riedl et al. 1972, Riedl \& Machan 1972, Harrison et al. 1983, Huettel \& Gust 1992); and seepage of hydrological fluid (Bokuniewicz 1980, Frape \& Paterson 1981). The latter 2 types of processes play a role

\footnotetext{
- Present address: Arbeitsbereich Meerestechnik 1, Technische Universität Hamburg-Harburg, W-2100 Hamburg 90 , Germany
}

in permeable sediments (Chilingar 1964, Webb 1969 , Chilingarian et al. 1972), while the first 2 are present in both impermeable and permeable sediments. Permeable sediments are a common feature in the marine environment, with examples from the intertidal flats of the Wadden Sea on the North Sea coast presented by Huettel (1990), and from the continental shelf by Riedl et al. (1972).

The tools to quantify the variety of nutrient, toxin and solute exchanges are mostly benthic chambers with circular and quadratic cross sections enclosing a sediment core plus overlying water column in which the time-dependent concentration build-up is monitored, core inserts in straight recirculation flumes and sediment-filled rotating annuli (Zeitzschel \& Davies 1978, Dyrssen et al. 1984, Holme \& Mclntyre 1984, Kirsten \& Jahnke 1985, Berelson et al. 1987). Of these, benthic stirred chambers have developed into a 
standard tool with the theoretical and experimental hydrodynamical background of diffusive solute transfer (e.g. see, Son \& Hanratty 1967, Boudreau \& Guinasso 1982, Santschi et al. 1983, Opdyke et al. 1987, Santschi et al. 1991) drawn mostly from research in chemical engineering and geochemical processes. Malan \& McLachlan (1991) present in their Table 2 an overview of flux experiments executed in stirred benthic chambers, Boynton et al. (1981) discuss the volume/area relationship for benthic flux chambers and Buchholtz et al. (1989) calibrated the bottom stress as a function of stirrer height and rate in a rectangular chamber, as has been done for the constant-stress devices of Gust (1989). For any selected chamber geometry, the stirrer rate (and if necessary stirrer height) can be adjusted to provide comparable bottom stress distributions (within a generous error margin), and observed increased fluxes of solutes or respiration rates have typically been interpreted by diffusive transfer processes requiring knowledge of only the bottom stress but not the concurrent pressure fields present in enclosed devices.

The use of jets or stirrers producing circular flow patterns inside the chambers or limited core sizes introduce, however, constraints which are uncommon in the natural environment (Huettel \& Gust 1991). To test the equivalency of interfacial solute exchange acquired in benthic chambers with those in the field and to provide a data base for the existing evaluation techniques of chamber results, we used dye releases to study the solute pathways and fluxes from permeable and impermeable sediments with smooth surfaces in stirred chambers under variation of all hydrodynamic driving forces and compared them with results from sediment cores exposed to unidirectional, 2-dimensional boundary layer flows under similar bottom stresses.

\section{MATERIALS AND METHODS}

The devices used for our experiments consisted of: (1) a cylindrical chamber of clear acrylic $30 \mathrm{~cm}$ high, $30 \mathrm{~cm}$ diameter) with $10 \mathrm{dm}^{3}$ sediment and 7 l chamber water agitated by either a horizontally rotating stirrer bar (20 cm long, $1.2 \mathrm{~cm}$ diameter) or a horizontally rotating disk of $20 \mathrm{~cm}$ diameter with $5 \mathrm{~cm}$ wide skirt attached perpendicular to its circumference (Gust 1989) (stirrer bar or disk, driven by $24 \mathrm{~V}$ DC motors, rotated $8 \mathrm{~cm}$ above the sediment core); and (2) a cubical chamber of clear acrylic $(30 \times 30 \times 30 \mathrm{~cm})$, containing $18 \mathrm{dm}^{3}$ of sediment and $9 \mathrm{l}$ of water stirred by a central horizontally rotating bar $(20 \mathrm{~cm}$ long, $1.2 \mathrm{~cm}$ diameter, $8 \mathrm{~cm}$ above core).

The interfacial solute exchange and porewater replacement recorded in these chambers for selected bottom stresses were compared to results obtained with a large sediment core $(175 \mathrm{~cm}$ long $\times 32 \mathrm{~cm}$ wide $\times 15 \mathrm{~cm}$ deep, $84 \mathrm{dm}^{3}$ volume) exposed to the same bottom stresses generated by 2 -dimensional flow in a straight recirculating flume $(6 \mathrm{~m}$ long $\times 30 \mathrm{~cm}$ wide $\times 20 \mathrm{~cm}$ deep). The recirculating water volume amounted to 280 l. During experimental runs, a heightvariable sharp-crested weir and tilting of the flume produced the required constant water depth of 4 to $5 \mathrm{~cm}$ height over the total core surface. Resulting constant static pressure at any surface location of the core was verified via measurements with a pressure differential gauge (see below).

We chose a dye-tracer method to measure interfacial solute exchange. Rhodamine-WT, which dyes the porewater, does not stain the sediment grains (loss in $30 \mathrm{~d}: 4.5 \pm 2.1 \%$ ) but kaolinite (loss in $30 \mathrm{~d}$ : $63 \pm 11 \%$ ), provided a suitable tracer for porewater exchange processes. Stirrer rpm and the flow speed in the flume were selected to generate comparable friction velocities $u$. (shear at the sediment water interface, expressed as friction velocities $u .=(\tau / \rho)^{1 / 2}$, where $\tau=$ bottom stress, $\rho=$ fluid density) at the sediment-water interface independent of device geometry and water depth. Sediment cores with smooth surfaces and dyed porewater throughout, exposed in chambers and flumes to comparable averaged friction velocities, produced increases of the dye concentration in the supernatant fluid from porewater release for each run. Dye concentration was quantified by spectrophotometrical analysis of sequentially drawn water samples. Sediment cores in cylinders with nonstirred supernatant water provided data for diffusive dye release.

The core sediments varied between 3 narrowranged size classes of abiotic, washed quartz sands except for the permeable natural cores from Kiel Bight, Germany, used for the oxygen measurements. Additionally, sediments composed of commercial glass beads, diatom shell powder, kaolinite and mixtures of kaolinite and fine sand were tested (Table 1). To prepare the cores, sediment and dyed water $(10 \%$ Rhodamine-WT solution) were intensely mixed and the ensuing red porewater/sediment mixture filled into the chambers or flume inserts while compacted by low frequency vibrations. Core surfaces were smoothed using a blade providing a sediment roughness comparable to the grain diameter.

In a short, square sediment core $(30 \times 30 \times 30 \mathrm{~cm})$ exposed to 2 -dimensional flow, we observed at the upstream transition from the impermeable-approaching bottom to the permeable sediment core the 'edge effect' depicted in Fig. 1. Water moved downwards right at this edge (maximum $7.5 \mathrm{~cm}$ in $24 \mathrm{~h}$ ), as evidenced by the alternating $2 \mathrm{~cm}$ thick horizontal layers 
Table 1 Characteristics of sediments used for experiments $\phi$ : grain size in phi notation; Q1: first quartile $(25 \%$ of grains smaller than this size): M: median; Q3: third quartile (25\% of grains larger than this size)

\begin{tabular}{|c|c|c|c|c|c|c|}
\hline Sediment type & $\phi$ & $\mathrm{Q} 1(\mu \mathrm{m})$ & $M(\mu \mathrm{m})$ & $\mathrm{Q} 3(\mu \mathrm{m})$ & Porosity $(\%)$ & Permeability $K(\mathrm{D})$ \\
\hline \multicolumn{7}{|l|}{ Sieved } \\
\hline Coarse sand (quartz) & 0.5 & 595 & 730 & 870 & 31.7 & 168.0 \\
\hline Medium sand (quartz) & 1.4 & 295 & 370 & 440 & 32.4 & 56.4 \\
\hline Fine sand (quartz) & 2.2 & 170 & 220 & 290 & 34.6 & 15.0 \\
\hline Coarse silt (glass beads) & 4.3 & & 50 & & 40.2 & 1.9 \\
\hline Fine silt (diatom powder) & 6.6 & & 10 & & 81.0 & 3.4 \\
\hline Very fine silt (kaolinite) & 8.0 & & 4 & & 64.5 & $2.6 \times 10^{-3}$ \\
\hline \multicolumn{7}{|l|}{ Mixed } \\
\hline Fine sand + kaolinite $195 \%$ & & & & & 39.0 & 5.0 \\
\hline Fine sand + kaolinite $(70 \%$ & & & & & 45.0 & $2.3 \times 10^{-2}$ \\
\hline \multicolumn{7}{|l|}{ Natural } \\
\hline Medium sand (quartz) & 1.5 & 210 & 350 & 410 & 32.8 & 54 \\
\hline
\end{tabular}

of dyed and non-dyed porewaters in coarse sand (grain size in $\phi$ notation $=0.5$ ) bending downwards at the upstream side of the core. Porewater emerged further downstream in a divergence zone, identified by upward movement of the upper dyed layers. Switching to a long sediment core $(175 \mathrm{~cm}$ long $\times 32 \mathrm{~cm}$ wide $x$ $15 \mathrm{~cm}$ deep) with fine dyed sediment $(\phi=2.2)$ exposed for $1 \mathrm{wk}$ to 2 -dimensional flow $\left(u .=0.8 \mathrm{~cm} \mathrm{~s}^{-1}\right)$ in the recirculating flume produced a similar triangular washout zone $(5 \mathrm{~cm}$ deep $\times 15 \mathrm{~cm}$ wide) at the upstream transition from the smooth impermeable flume surface to the permeable sediment surface, and additional zones close to the sidewalls $(3 \mathrm{~cm}$ deep $\times 2 \mathrm{~cm}$ wide) caused by longitudinal helicals (Hunt \& Joubert 1979).

These wall and edge effects contributed approximately $37 \%$ (upstream transition) and $17 \%$ (sidewalls) to the total dye release from the core surface in $24 \mathrm{~h}$

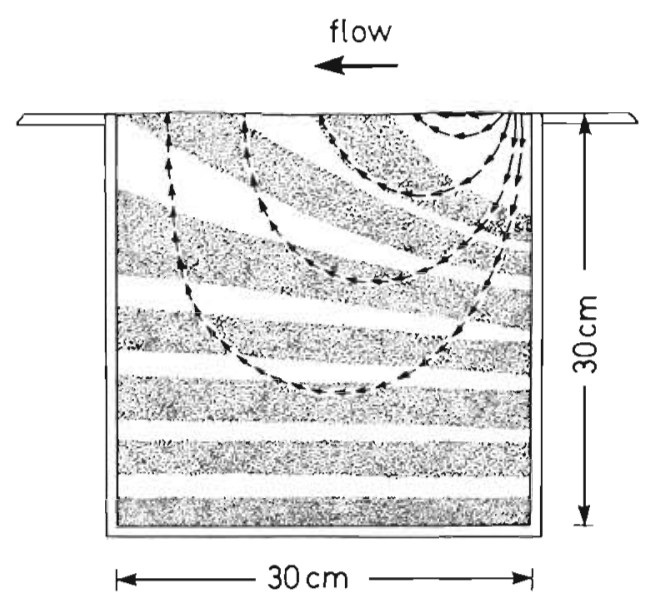

Fig. 1 Short square sediment core $(\phi=0.5)$ exposed to 2dimensional flow $\left(u .=0.7 \mathrm{~cm} \mathrm{~s}^{-1}, t=24 \mathrm{~h}\right)$. The streamlines of water are based on movement of the initially horizontal dyed porewater layers (shaded areas) and had to be eliminated to obtain a representative field-simulating core. For our control runs, this was achieved by preparing the sediment cores with 'buffer zones', non-dyed porewater adjacent to the sidewalls in a $3.5 \mathrm{~cm}$ wide zone, and at the up-and downstream edges in 20 and $15 \mathrm{~cm}$ wide zones, respectively. By this approach we excluded wall and edge effects from the dye flux data; washout depth did not exceed $1.5 \mathrm{~cm}$ anywhere in the dyed core. The flux-surface area of the embedded red core thus had a length of $140 \mathrm{~cm}$ and a width of $25 \mathrm{~cm}\left(3500 \mathrm{~cm}^{2}\right)$, and we refer to this particular set-up henceforth as 'reference core'. The dilution of dye due to the flushing of the buffer zones is negligible (4 1 non-dyed porefluid at the most was added to the total volume of $280 \mathrm{l}$ flume water). Erosion at the bottom/sand transition of the core limited the maximum friction velocity for the flume runs to $u_{.}=0.8 \mathrm{~cm} \mathrm{~s}^{-1}$.

After starting stirrer motors or flume pump, $3 \mathrm{ml}$ samples ( $n=3$ ) of chamber or flume waters were taken in intervals ranging from $5 \mathrm{~min}$ (during the initial phase) to $2 \mathrm{~h}$ towards the end of the $24 \mathrm{~h}$ runs. Since the advective porewater flow turned out to be the dominant process governing interfacial dye exchange for permeable chamber cores, dye fluxes corresponded to dyed porewater fluxes. Thus, all dye release volumes and fluxes, listed in tables and as ordinate values of figures, are expressed in volumes of the initial dye concentration used to prepare each individual core. All time series of supernatant water samples thus included reference samples $(n=5)$ of the original core dye. To allow comparison, the flume and no-flow dye release data, both approximating diffusive dye release, are presented using dyed porewater volume equivalents as well. The volumes of released dye from the cores were determined by comparing the absorbance data obtained from experimental runs to absorbance data collected in chamber and flume calibration runs with 
dye-water mixtures of volumetric-established, known dye concentrations.

The dyed porewater release was not identical to the total amount of fluid flushed through the sediment per run time since the washed-out dyed pore fluid was continuously replaced by (non-dyed) intruding supernatant water. Assuming that the steepest dye concentration increase in the supernatant water during the initial experiment phase for flume and chambers was caused by flushing of the uppermost sediment layer and that the final flux measured for the flume core was limited by molecular diffusion, the initial dye fluxes (average of the first $2 \mathrm{~h}$ per core) minus the final dye fluxes (average of the last $2 \mathrm{~h}$ from the reference core) multiplied by 24 , yields the (minimum) volume of porewater flushed during a $24 \mathrm{~h}$ run per device. The washout depth given in Table 2 identifies the layer thickness beneath which the porewater/sediment mixture retained its initially red color.

Table 2. Dye fluxes, flushing rates and washout depths for stirred chambers and flume core. In 1 flume run with $u .=0.3 \mathrm{~cm} s^{-1}$ the initial flux was increased by incomplete mixing of released dye and supernatant water [value in brackets]. Cyl.. cylinder; cub.: cube; dsk: disk; diatom pow.: diatom shell powder; kaol.. kaolinite

\begin{tabular}{|c|c|c|c|c|c|c|c|c|c|}
\hline $\begin{array}{l}\text { Device } \\
\text { design/stirr }\end{array}$ & $\begin{array}{l}\text { Sediment } \\
\text { type }\end{array}$ & 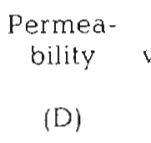 & $\begin{array}{l}\text { Friction } \\
\text { velocity } u \text {. } \\
\left(\mathrm{cm} \mathrm{s}^{-1}\right)\end{array}$ & $\begin{array}{c}\text { Rotating } \\
\text { stirrer } \\
\text { (rpm) }\end{array}$ & $\begin{array}{c}\text { Initial } \\
\text { dye flux } \\
0-2 \mathrm{~h} \\
\left(\mathrm{ml} \mathrm{m}^{-2} \mathrm{~h}^{-1}\right)\end{array}$ & $\begin{array}{c}\text { Final } \\
\text { dye flux } \\
22-24 \mathrm{~h} \\
\left(\mathrm{ml} \mathrm{m} \mathrm{m}^{-2} \mathrm{~h}^{-1}\right)\end{array}$ & $\begin{array}{l}\text { Water flushed } \\
\text { through core } \\
\text { in } 24 \mathrm{~h} \\
\left(1 \mathrm{~m}^{-2}\right)\end{array}$ & $\begin{array}{l}\text { Dye } \\
\text { released } \\
\text { in } 24 \mathrm{~h} \\
\left(\mathrm{l} \mathrm{m}^{-2}\right)\end{array}$ & $\begin{array}{l}\text { Maximum } \\
\text { washout } \\
\text { depth } \\
(\mathrm{mm})\end{array}$ \\
\hline \multicolumn{10}{|c|}{ Chambers with central rotating agitator } \\
\hline Cyl. & Kaolinite & $2.6 \times 10^{-3}$ & 0.0 & 0 & - & - & - & 3.2 & 0 \\
\hline Cyl./dsk & Kaolinite & $2.6 \times 10^{-3}$ & 0.5 & 13 & 590 & 100 & - & 4.6 & 0 \\
\hline Cyl./dsk & Kaolinite & $2.6 \times 10^{-3}$ & 1.0 & 36 & 320 & 110 & - & 5.8 & 0.5 \\
\hline Cyl./dsk & Diatom pow. & 34 & 0.5 & 13 & 270 & 160 & - & 4.1 & 5 \\
\hline Cyl./dsk & Glass beads & 1.9 & 0.3 & 5 & 230 & 50 & - & 2.1 & 6 \\
\hline Cyl./dsk & Sand +kaol. $(30 \%)$ & $2.3 \times 10^{-3}$ & 0.8 & 28 & 450 & 140 & - & 5.2 & 0.5 \\
\hline Cyl./dsk & Sand +kaol. $(5 \%)$ & 5 & 0.8 & 28 & 590 & 190 & 12.5 & 7.1 & 40 \\
\hline Cyl. & Sand & 15 & 0.0 & 0 & - & 10 & - & 0.9 & 0 \\
\hline Cub./bar & Sand & 15 & 0.2 & 10 & 190 & 50 & 4.1 & 1.7 & 8 \\
\hline Cyl./dsk & Sand & 15 & 0.5 & 13 & 480 & 150 & 10.4 & 6.7 & 35 \\
\hline Cyl./dsk & Sand & 15 & 0.5 & 13 & 500 & 180 & 10.9 & 6.8 & 39 \\
\hline Cyl./dsk & Sand & 15 & 0.5 & 13 & 500 & 170 & 10.9 & 6.8 & 40 \\
\hline Cyl./bar & Sand & 15 & 0.5 & 12 & 570 & 180 & 12.6 & 7.2 & 38 \\
\hline Cub./bar & Sand & 15 & 0.5 & 20 & 390 & 150 & 8.3 & 5.5 & 25 \\
\hline Cyl./dsk & Sand & 15 & 0.7 & 23 & 710 & 320 & 15.5 & 12.0 & 53 \\
\hline Cyl./bar & Sand & 15 & 0.7 & 20 & 1090 & 360 & 24.7 & 14.7 & 53 \\
\hline Cyl./dsk & Sand & 15 & 1.0 & 36 & 1720 & 470 & 39.2 & 20.9 & 90 \\
\hline Cyl/dsk & Sand & 15 & 1.0 & 40 & 1500 & 390 & 33.9 & 17.3 & 78 \\
\hline Cyl/bar & Sand & 15 & 1.0 & 38 & 1430 & 480 & 32.2 & 18.3 & 87 \\
\hline Cub./bar & Sand & 15 & 1.0 & 40 & 1160 & 430 & 25.7 & 17.0 & 85 \\
\hline Cyl. & Sand & 56.4 & 0.0 & 0 & - & - & - & 0.9 & 0 \\
\hline Cyl./dsk & Sand & 56.4 & 0.5 & 13 & 1100 & 130 & 25.3 & 9.3 & 60 \\
\hline Cyl./dsk & Sand & 56.4 & 1.0 & 36 & 6880 & 430 & 163.0 & 45.2 & 130 \\
\hline Cyl. & Sand & 168 & 0.0 & 0 & - & - & - & 0.8 & 0 \\
\hline Cyl./dsk & Sand & 168 & 0.5 & 13 & 3650 & 540 & 86.5 & 27.1 & 102 \\
\hline Cyl./dsk & Sand & 168 & 1.0 & 36 & 17630 & 430 & 421.0 & 64.9 & 165 \\
\hline \multicolumn{10}{|c|}{ Reference flume core } \\
\hline \multirow[t]{14}{*}{ Flume core } & Diatom pow. & 3.4 & 0.3 & - & 150 & 60 & - & 2.0 & 1 \\
\hline & Sand & 15 & 0.0 & - & - & 10 & - & 0.8 & 0 \\
\hline & Sand & 15 & 0.2 & - & 130 & 20 & 2.7 & 1.3 & 2 \\
\hline & Sand & 15 & 0.3 & - & {$[360]$} & 20 & - & 1.4 & 2 \\
\hline & Sand & 15 & 0.3 & - & 150 & 30 & 2.7 & 1.5 & 2 \\
\hline & Sand & 15 & 0.4 & - & 200 & 30 & 3.9 & 1.5 & 5 \\
\hline & Sand & 15 & 0.5 & - & 260 & 40 & 5.2 & 1.7 & 5 \\
\hline & Sand & 15 & 0.5 & - & 220 & 40 & 4.2 & 1.6 & 5 \\
\hline & Sand & 15 & 0.6 & - & 280 & 50 & 5.4 & 2.0 & 6 \\
\hline & Sand & 15 & 0.6 & - & 300 & 50 & 5.9 & 2.2 & 6 \\
\hline & Sand & 15 & 0.7 & - & 420 & 60 & 8.6 & 2.6 & 7 \\
\hline & Sand & 15 & 0.8 & - & 490 & 80 & 10.1 & 3.4 & 10 \\
\hline & Sand & 15 & 0.8 & - & 550 & 90 & 11.5 & 3.7 & 10 \\
\hline & Sand & 168 & 0.3 & - & 170 & 30 & 3.4 & 1.3 & 2 \\
\hline
\end{tabular}


The bottom stresses generated inside the chambers and in the flume were measured by flush-mounted hot-film sensors connected to constant-temperature anemometers (Gust 1988). For flow velocities, metalclad hot-wires (Gust 1982) were used, and pore pressures were obtained by an inductive wet/wet differential pressure gauge of high sensitivity connected to a frequency carrier bridge. All sensors were calibrated in the laboratory with relative uncertainties $<3 \%$. A polarographic micro-electrode was utilized for the porewater oxygen profile measurements.

\section{RESULTS}

In the reference cores with fine sediment ( $\phi=2.2$ ), the volume of dye released in $24 \mathrm{~h}$ grew multiplicatively from 1.3 to $3.71 \mathrm{~m}^{-2}$ with friction velocity $u$. increasing from 0.2 to $0.8 \mathrm{~cm} \mathrm{~s}^{-1}$ (Table 2, Fig. 2b). The associated dye fluxes achieved equilibrium values of 20 to $90 \mathrm{ml} \mathrm{m}^{-2} \mathrm{~h}^{-1}$ after run times $>10 \mathrm{~h}$. The dye washout depths did not exceed $1.0 \mathrm{~cm}$ after $24 \mathrm{~h}$ runs (Fig. 2c). Evenly distributed pink color of the sediment surface during the runs gave evidence of a uniform dye release over the whole surface area during the runs and proved that advective porewater processes due to interactions between microtopography and flow (Huettel \& Gust 1992) were reduced to a minimum. Caused by the wall shearing stress, up to $11 \mathrm{l} \mathrm{m}^{-2}$ of flume water were flushed through the uppermost sediment layer during a $24 \mathrm{~h}$ run within a washout layer $<1.0 \mathrm{~cm}$, even at a $u$. of $0.8 \mathrm{~cm} \mathrm{~s}^{-1}$.

In sediment cores composed of fine sand ( $\phi=2.2$ ) and exposed to a circular flow pattern in chambers with a central rotating agitator, dye fluxes, volumes of dye released in $24 \mathrm{~h}$, water flushed through the sediment and visible washout depth significantly exceeded the corresponding measurements in the reference core as shown in Table 2 and Fig. 2 (for statistics see below). For friction velocities ranging from 0.2 to $0.7 \mathrm{~cm} \mathrm{~s}^{-1}$ (runs in the $u$. range of the reference flume), fluxes from 50 to $360 \mathrm{ml} \mathrm{m}^{-2} \mathrm{~h}^{-1}$ exceeded those of the flume core 2.5- to 6.0-fold (Fig. 2a) and the volume of dye released in $24 \mathrm{~h}\left(1.7\right.$ to $\left.14.7 \mathrm{l} \mathrm{m}^{-2}\right)$ was 1.3 to 5.7 times larger (Fig. 2b). Volumes of water flushed through the sediment in the stirred chambers (4 to $25 \mathrm{l} \mathrm{m}^{-2}$ ) exceeded those of the reference flume core by a factor ranging from 1.5 to 3.0 , and the washout depths $(0.8$ to $5.3 \mathrm{~cm})$ surpassed those recorded in the flume 4 - to 8 -fold (Fig. 2c) for our sediment and friction velocity range selected. These results propose for permeable sediments a different pathway of interfacial solute exchange in stirred chambers compared to the reference cores.
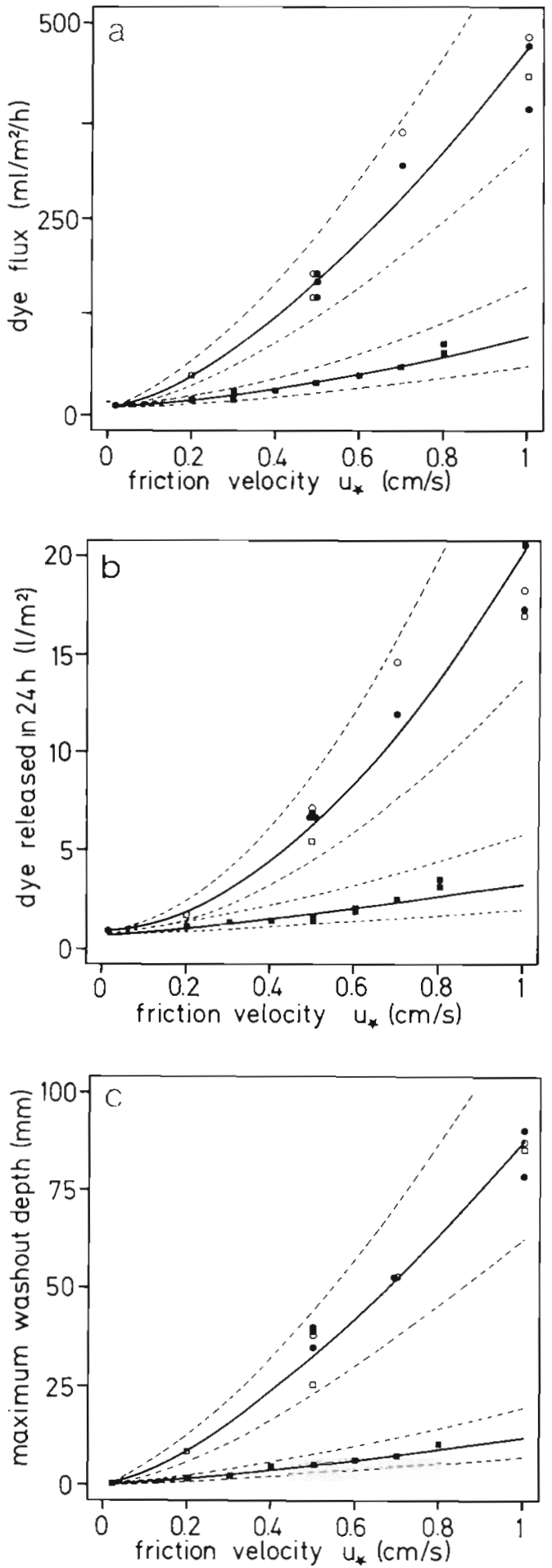

Fig. 2. (a) Final dyed porewater fluxes (average of the 22 to $24 \mathrm{~h}$ interval), (b) volumes of dyed dyed porewater released in $24 \mathrm{~h}$, and (c) maximum dye washout depth in $24 \mathrm{~h}$ in chambers and reference flume core for fine sediment $(\phi=2.2)$ at non-eroding friction velocities $(u$.$) . Dashed lines represent$ the $95 \%$ prediction limits. (-) Reference flume core; ( $\square$ ) cubical chamber with rotating stirrer bar; (0) cylindrical chamber with rotating bar; $(\bullet)$ cylindrical chamber with rotating disk 
In our experiments with fine sand ( $\phi=2.2)$, the shape of the central agitator (stirrer bar vs disk) and the geometry of the chamber (round vs square) had no measurable influence on the interfacial solute exchange at comparable $u_{*}$, permitting us to pool the flux results from all tested chambers as a single sample set for regression analysis $(n=12)$. Compared with the data set from the reference core at same sediment type and subcritical friction velocities ( $n=10$ ), the dye flux. the dye concentration build-up in the chamber water, as well as the penetration depth of overlying water into the sediment increased at multiplicative rates with increasing friction velocity $u$. The prediction limits (dashed lines $=95 \%$ limits; shown in Fig. $2 \mathrm{a}, \mathrm{b} \& \mathrm{c}$ ) confine the area where $95 \%$ of the results produced with our stirred chambers can be expected. They overlap the prediction area (95\% limits) of the flume core data only at low friction velocities, documenting that fluxes obtained at $u .>0.2 \mathrm{~cm} \mathrm{~s}^{-1}$ in the stirred chambers significantly exceeded those of the reference core. As shown in Fig. 3 for $u .=0,0.5$ and $1.0 \mathrm{~cm} \mathrm{~s}^{-1}$, the dye released in the stirred chamber grew with increasing permeability of the sediment.

Our experimental procedures generated 2 independent data sets from the reference cores and the chamber cores. The resulting paired dye flux observations at comparable friction velocity permitted a simple test of statistical significance of the contention that solute fluxes are independent of device confinement for permeable sediments. Using a sign test format (Beyer

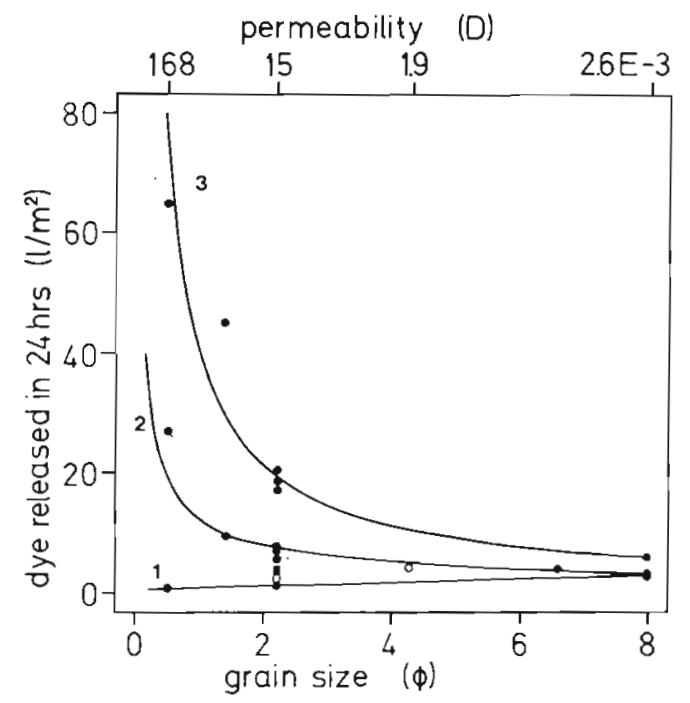

Fig. 3. Dye released in $24 \mathrm{~h}$ in stirred chambers with sediments of different permeabilities at $u .=0 \mathrm{~cm} \mathrm{~s}^{-1}(1) .0 .5 \mathrm{~cm}$ $\mathrm{s}^{-1}(2)$ and $1.0 \mathrm{~cm} \mathrm{~s}^{-1}$ (3). (…...) $95 \%$ confidence limits for the regression curves. Squares at $\phi=2.2$ represent dye releases measured in the reference flume core at $u$. $=0.5 \mathrm{~cm} \mathrm{~s}^{-1}$ (a) and $u .=0.8 \mathrm{~cm} \mathrm{~s}^{-1}(0)$. (0) at $\phi=4.3$ is a chamber run with sediments composed of glass beads at $u .=0.3 \mathrm{~cm} \mathrm{~s}^{-1}$
1968, Daniel 1978), paired flux observation per same friction velocity can be assigned a positive sign (+) when higher fluxes are observed in the chamber, and a negative sign (-) when reference core data are higher. It follows that for 8 paired observations at $u .<0.8 \mathrm{~cm}$ $\mathrm{s}^{-1}$ (Table 2) with no (-) result (Bowker \& Liebermann 1972), the hypothesis that chamber flux results are equivalent to reference core (i.e. field) results can be rejected at the $1 \%$ significance level for the fine, permeable sediment and friction velocity range tested.

Immediately after starting the stirrer motor, a bottom stress field was established at the water/sediment interface in the chambers. Lower pressure in the center and increasing pressure towards the chamber wall developed (Fig. 4), since centrifugal forces drove the water towards the circumference of the chambers, producing a horizontal pressure gradient (Prandtl \& Tietjens 1957). A secondary circulation pattern evolved in the supernatant fluid with water moving upwards in the center and downwards close to the sidewall where some of the chamber water intruded the permeable sediment. Water entering the pore space at the circumference of the core decolorized the sand adjacent to the transparent sidewall and a dye plume formed in the center of the rotating water column from emerging porewater. Tightening the secondary circulation by lowering the stirrer disk enhanced water intrusion into the sediment (Fig. 5) while increasing the water level above the stirrer disk had no significant effect on the dye washout. Coupling of the stirrer-generated boundary layer flow inside the chamber with the porewater movement via a Couettetype shear flow could be excluded as a driving force of the advective porewater flow by placing a $1 \mathrm{~cm}$ high plastic grid ( $1 \times 1 \mathrm{~cm}$ grid holes) onto the sediment surface, effectively eliminating horizontal movement of supernatant water near the interface. Advective porewater flow as well as the dye washout pattern remained the same in this run as observed when

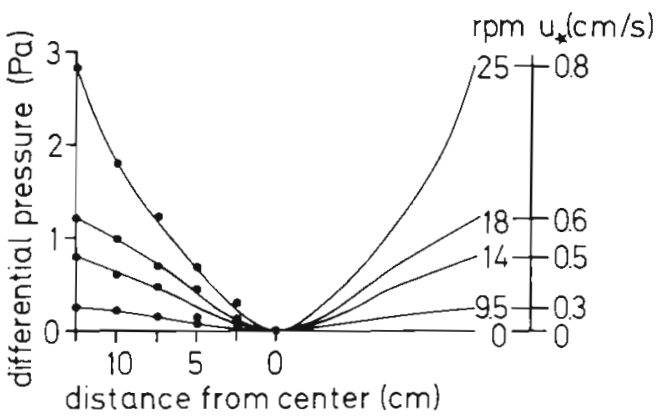

Fig. 4. Radial differential pressures at the sediment surface between center and distance from center in a cylindrical chamber ( $25 \mathrm{~cm}$ diameter, $30 \mathrm{~cm}$ height) with central rotating disk (20 cm diameter) at different rpm for $10 \mathrm{~cm}$ water height above sediment ( $1 \mathrm{~Pa}=10 \mu \mathrm{bar})$ 


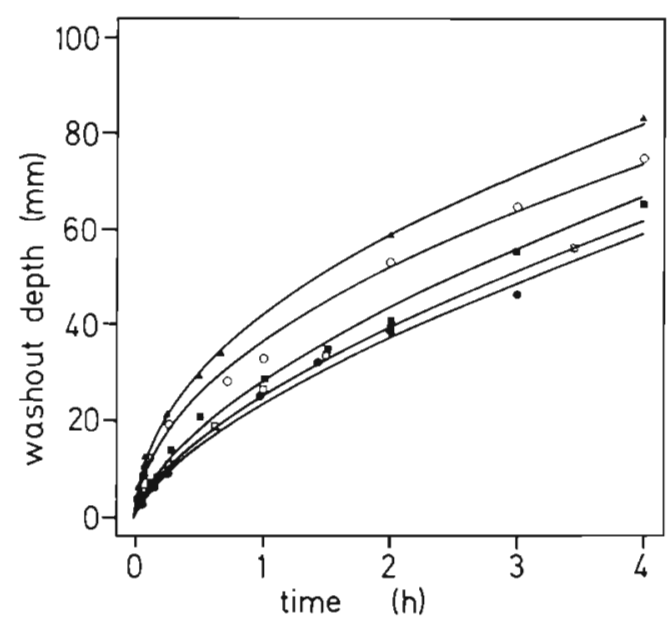

Fig. 5. Washout depth close to the wall of cylindrical chamber as a function of time for different distances between the stirring disk (flat disk, $20 \mathrm{~cm}$ diameter, rotating at $38 \mathrm{rpm}$ ) and the sediment surface (medium grain size, $\phi=1.4, K=56.4 \mathrm{D}$ ) Distance above surface: (•) $20 \mathrm{~cm}$; () $15 \mathrm{~cm}$; (-) $10 \mathrm{~cm}$; (o) $5 \mathrm{~cm} ;(1) 2 \mathrm{~cm}$

pressure gradient and friction velocity acted simultaneously, with the measured concentration build-up comparable to that of the core without grid $(\phi=2.2$, $17.3 \mathrm{l} \mathrm{m}^{-2}$ in $24 \mathrm{~h}, u .=1.0 \mathrm{~cm} \mathrm{~s}^{-1}$ ). This experiment demonstrates that in the chambers the observed dye release is predominantly driven by the pressure gradients, in contrast to the reference cores where the horizontal pressure gradient was zero, and friction velocity $u_{\bullet}$, together with the Schmidt number, controlled the release (Opdyke et al. 1987).

During each experiment with permeable sediment, the initially narrow ring of decolorized sediment at the interface grew steadily from the outside wall towards the center while deepening. At $u$. of $0.5 \mathrm{~cm} \mathrm{~s}^{-1}$ and sediment with a grain size of $\phi=2.2$ (median grain size distribution $\mathrm{d}_{50}=220 \mu \mathrm{m}$, permeability $K=15$ Darcy; $D$ ), dye washout depth near the chamber wall reached $3 \mathrm{~cm}$ depth after $1 \mathrm{~d}$, continuously growing deeper and passing $6.5 \mathrm{~cm}$ after $5 \mathrm{~d}$. No equilibrium washout depth could be reached even after $10 \mathrm{~d}$ of operation. In medium sand $(\phi=1.4)$ vertical porewater velocity during the first hour of the runs reached $30 \mathrm{~mm} \mathrm{~h}^{-1}$ with the stirring disk rotating at $38 \mathrm{rpm} 10 \mathrm{~cm}$ above the sediment surface $\left(u_{\bullet} \approx 1.0 \mathrm{~cm} \mathrm{~s}^{-1}\right.$; Fig. 5). In coarse sediment $\left(\phi=0.5, d_{50}=730 \mu \mathrm{m}, K=168 \mathrm{D}\right)$ the washout depth grew continuously and reached the bottom at $18 \mathrm{~cm}$ after $2 \mathrm{~d}$ at $u .=0.8 \mathrm{~cm} \mathrm{~s}^{-1}$. In contrast, for the smooth reference flume core with $\phi=2.2$, the washout depth of $0.5 \mathrm{~cm}$ showed no significant changes over $1 \mathrm{wk}$ at a friction velocity $u_{\bullet}=0.5 \mathrm{~cm} \mathrm{~s}^{-1}$ and did not exceed $1.5 \mathrm{~cm}$ for coarser sediment $(\phi=0.5)$ during a $2 \mathrm{~d}$ period, respectively. Chamber-internal circular flows caused porewater washout in sediments composed of diatom fragments ( $\phi=6.6$, permeability $K=3.4 \mathrm{D}$ ) and glass beads ( $\phi=4.3$, permeability $K=1.9 \mathrm{D})$ as well (Table 2 ).

Dissection of the cores after $24 \mathrm{~h}$ revealed for all permeable sediments an axisymmetric dye washout pattern, deepest at the sidewalls and concavely bent towards the center area (Fig. 6a). The paths of porewater movement were obtained from the displacement of injected dye dots and of originally horizontal alternating red and white layers, all drawn to the surface in the center part while moving downward close to thechamber wall (Fig. 6b). Porewater moved in radial

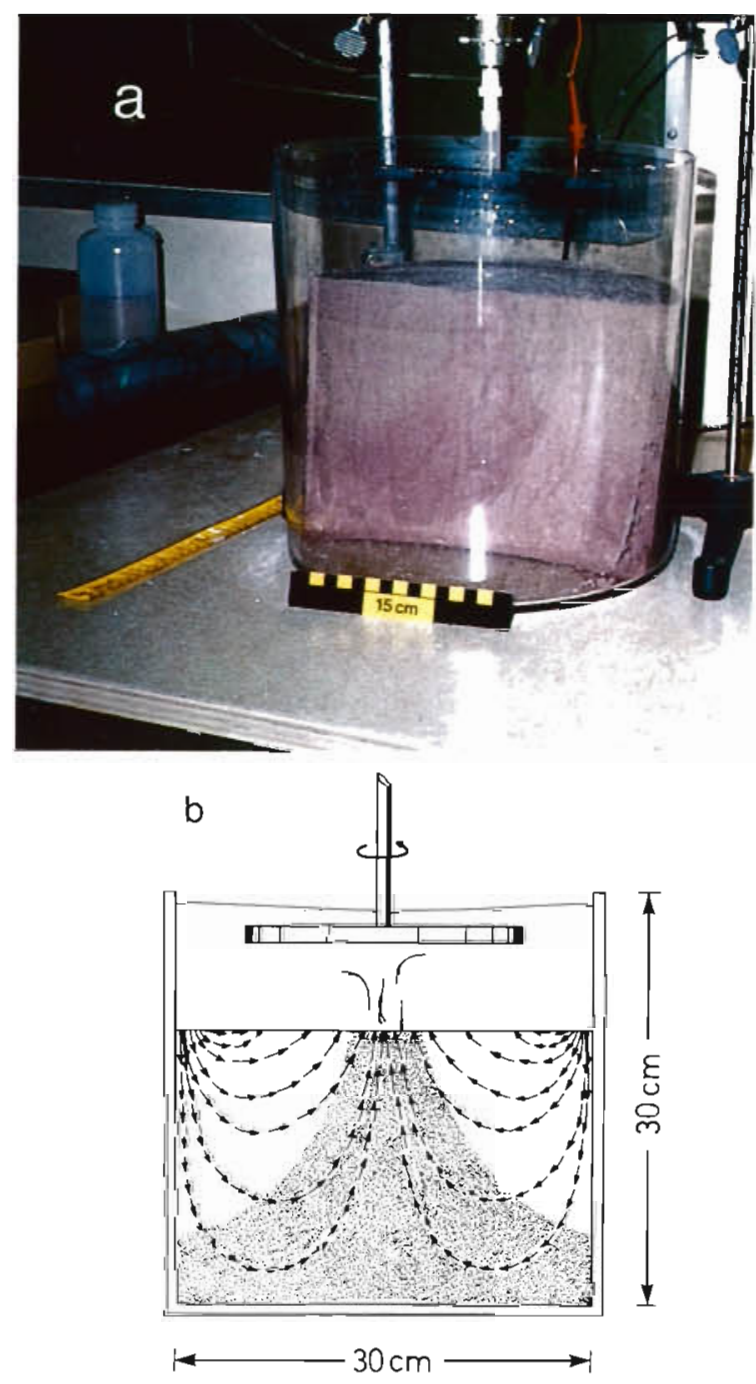

Fig. 6. Sediment core in the cylindrical chamber exposed to circular flow $\left(\phi=2.2, u\right.$. $\left.=0.5 \mathrm{~cm} \mathrm{~s}^{-1}, t=9 \mathrm{~d}\right)$. (a) Coneshaped porewater advection chimney. Undyed chamber water replaced the red porewater between sidewall and the advection chimney. Note that porefluid emergence occurs over the whole surface area except for a zone close to the wall. (b) Porewater (dyed and undyed) moves continuously along streamlines symbolized by the small arrows as found by injecting dye dots into the sediment. The shaded area represents the diminishing dyed area 
planes, confirmed by chamber experiments monitoring the displacement of single, vertically aligned dyed porewater columns. Switching from a stand-alone, bottom-sealed chamber with $18 \mathrm{~cm}$ core depth to a bottomless chamber, pushed $20 \mathrm{~cm}$ deep into a large, $80 \mathrm{~cm}$ deep submerged sediment reservoir $(\phi=2.2)$ with no outer flow did not change porewater flow features and dye release rates during a $5 \mathrm{~d}$ test.

Oxygen profiles measured in a natural sandy sediment core without macrofauna from Kiel Bight $(\phi=$ 1.5), kept for a month in a cylindrical chamber $(25 \mathrm{~cm}$ diameter, $30 \mathrm{~cm}$ height) stirred by a central rotating disk $(15 \mathrm{~cm}$ diameter $7 \mathrm{~cm}$ above core, operating at $20 \mathrm{rpm}$ approximating $u_{\boldsymbol{e}}=0.6 \mathrm{~cm} \mathrm{~s}^{-1}$ ), demonstrate the importance of device-induced advective flows for geochemical processes and microzonation in the porespace of natural sediments. Chamber water intruded the core adjacent to the enclosing circumference and carried oxygen into deeper sediment layers along the previously established dye washout paths. As a result, the depth of the light brown oxidized upper sediment layer grew with radial distance from the center reaching $2.5 \mathrm{~cm}$ at the circumference of the core. Free oxygen was detected down to $1.9 \mathrm{~cm}$ into the sediment close to the sidewall of the chamber (Fig. 7), while simultaneously upwelling porewater created an anoxic zone in the center of the core, visible as a black circular area on the surface. That this pattern occurs as result of the circular chamber flow was demonstrated by a control core in the same chamber, for which the water column, randomly mixed by air bubbles, produced a uniform oxidized surface layer with a depth not exceeding $0.3 \mathrm{~cm}$ and no free oxygen was found deeper than $0.2 \mathrm{~cm}$.

\section{DISCUSSION}

Our experiments reveal that confined permeable sediment cores exposed to circular or 2-dimensional boundary flow release solutes at rates higher than from a reference core. Causes are device-generated pressure gradients which enforce advective porewater flushing. These pressure gradients are induced by (1) edge- and sidewall effects in cores under unidirectional flow (2) circular flow patterns and (3) different flow regimes between outside boundary layer and chamber interior (see below). Pressure gradients, even in the $1 \mathrm{~Pa}$ range assumed initially to be negligible, drove chamber water into the porespace of the permeable sediments close to walls or edges, pushing porewater across the sediment interface in the core center and in divergence zones. Fluxes in confined chamber cores increased multiplicatively by a factor up to 6 with increasing friction velocity or pressure gradient at the

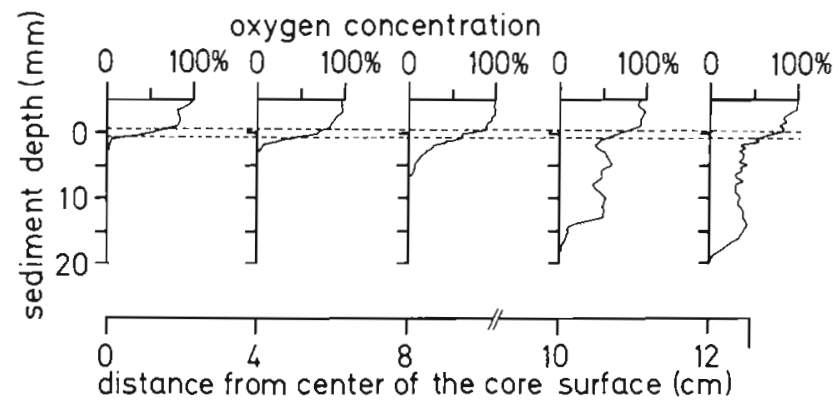

Fig. 7. Oxygen profiles measured in a natural sandy sediment core $\left(10 \mathrm{dm}^{3}\right)$, originating from Kiel Bight which was incubated for $4 \mathrm{wk}$ in a cylindrical chamber stirred with a disk of $15 \mathrm{~cm}$ diameter, rotating centrally $7 \mathrm{~cm}$ above the sediment surface at $20 \mathrm{rpm}\left(u .=0.6 \mathrm{~cm} \mathrm{~s}^{-1}\right)$. Dashed lines indicate sediment surface

interface relative to the fluxes recorded in the fieldsimulating reference core with smooth interface. In the reference core, interfacial solute exchange was governed by diffusion, which depended on the friction velocity $u$. applied (Opdyke et al. 1987). However, the increase of dye fluxes with increasing $u$. was much weaker in the reference cores compared to the chamber cores.

Most significantly, in chambers the dye release was found to be largely controlled by pressure-driven advective porewater release, which increased with permeability from fine to coarse sediments (Fig. 3). Our experiments were conducted with sieved quartz sands, glass beads and clean diatom powder with permeabilities ranging from 1.9 to $168 \mathrm{D}$ allowing relatively strong advective porewater exchange. Natural marine sediments are usually a mixture of different components including silt, clays and organic materials which decrease the permeability. Tsvetkova (1954) showed that permeability of sand decreases exponentially with increasing contents of kaolinite or other fine clay minerals. Adding $5 \%$ of kaolinite lowers the permeability of fine sand with $\mathrm{d}_{50}=350$ to $500 \mu \mathrm{m} 4$-fold, a clay contents of $10 \%$ decreases the permeability to $6 \%$, and kaolinite contents exceeding $20 \%$ result in almost impermeable sediments. Thus, muddy sediments of (nearly) impermeable nature will be little affected by advective processes as demonstrated in our experiments with sand-clay mixtures, in which case equivalency between solute fluxes in chambers and in the field can be expected for comparable friction velocities. An increase in fluxes may, however, occur in cohesive sediments when burrows of benthic animals, layers of fecal pellets, and detritus or skeletal materials (e.g. shell and diatom fragments) lead to a secondary permeability in the upper sediment layers (Risk \& Moffat 1977). 
In our dye experiments, Rhodamine-WT only traced the porewater flow and represented the flux of inert solutes. Its pathways indicated that when investigating fluxes of nutrients and other reactive solutes, chamberinduced porewater pumping may provoke flux data far removed from those of natural sediments as a result of device-specific displacement of geochemical reaction zones (coupled to non-typical porewater flow patterns). Our stirred chambers with fine sand may serve to demonstrate this point. Up to a 3 -fold water volume was flushed through the upper sediment layer compared to the reference core, and water intrusion depth exceeded that of the flume core up to 8-fold. Oxygen transported with this water into deeper sediment layers inside the chamber than in the reference core (see Fig. 7) will enhance nitrification locally and thereby increase nitrate concentrations (Blackburn \& Henriksen 1983). Hydrogen sulfide and other reduced substances in the anoxic sediment layers are likewise oxidized, increasing the oxygen consumption of the confined sediment core and the chamber at large. On the other hand, solutes from the anoxic zone, drawn to the surface with the advective porewater flow, will cause reductive processes in the uppermost sediment layer in the center of the core and divergence zones, thus releasing hydrogen sulfide and other reduced substances (e.g. ammonia and methane) into the chamber water. The resulting shifts in redox and $\mathrm{pH}$ isolines can enact release of redox sensitive substances such as phosphate and heavy metals (Hallberg et al. 1972, Balzer 1986), all of which may be correct for the particular geochemical chamber system, but not necessarily for in situ processes.

In marine sediments, a major pathway for interfacial solute flux is the bioturbation by benthic animals, which enhances solute exchange processes by burrowing, sediment mixing and irrigation (Gust \& Harrison 1981, Aller 1982, Rhoads \& Boyer 1982, Van der Loeff et al. 1984, Huettel 1990). Most of these animals are sensitive to the oxygen and hydrogen sulfide concentrations of the water and the inhabited sediment layer, and change their behavioral pattern accordingly (Reise 1985). In a chamber pumping oxygenated water into the sediment, a bottom dweller may thus choose a deeper, safer sediment layer for its burrow and may even abandon its normal irrigation and ventilation activities if enough oxygen is provided by the down-moving chamber water (applicable especially to U-shaped burrows). Meiofauna, benthic microalgae and bacteria will respond to the ensuing new microzonation of the sediment core. In experiments with relatively short durations, measured solute fluxes may thus reflect a series of exceptional processes rather than a particular biogeochemical steady state.
In this work we focused on chambers with sealed bottoms frequently used for laboratory investigations. We also obtained some first indications on the behavior of stirred chambers used in situ, where they are exposed to outside flow and penetrate the sediment to some depth. In general, additional pressure effects of a velocity-dependent magnitude can be anticipated. Furthermore the total pressure effect from chamber stirring and outside flow on the solute release inside the confined permeable core depended on the actual penetration depth of the chamber sidewalls. For example, in a bottomless cylindrical chamber pushed $2 \mathrm{~cm}$ deep into a large core of fine sand $(\phi=2.2)$ and submerged in stagnant water, circular stirring flow caused advective porewater flow patterns which exchanged flume and chamber water through the porespace underneath the chamber wall. Red porewater then emerged from sediment outside the chamber indicating porewater flow from inside to outside. Drained chamber fluid was replaced by dyed porewater. Dyed porewater release recorded in a bell jar $(25 \mathrm{~cm}$ diameter, $12 \mathrm{~cm}$ height) with rotating stirrer bar, resting on a smooth sediment surface, amounted to $5.2 \mathrm{l} \mathrm{m}^{-2} \mathrm{~d}^{-1}$ when exposed to outside flume flow of $10 \mathrm{~cm} \mathrm{~s}^{-1}$ (Fig. 8a). Dyed porewater release from the same jar, when submerged in stagnant water, decreased to less than $50 \%$ of the former value at $2.5 \mathrm{l} \mathrm{m}^{-2} \mathrm{~d}^{-1}$. This difference is attributed to the local flow acceleration above the chamber, which generates a pressure field around the jar such that a relative negative pressure gradient exists between inside and the outside of the enclosure (Fig. 8b). These additional pressure gradients, depending on the strength and nature of the outside boundary layer flow, exchange water beneath the chamber rim and cause increased porewater release inside the chamber. Minimum chamber penetration depth to de-couple chamber solute fluxes from outside-flow effects will depend on chamber geometry, sediment permeability, selected stirring strength and outside flow characteristics; this area requires further investigations. In addition to these observed steadystate flow effects, for which no statistical evaluation can be presently presented due to the purely observational character of the few runs executed, it is suggested that in areas with waves and/or wave-current boundary layers the particulars of solute releases and respiration data obtained by chambers pushed to selective depths into permeable sediments should be reviewed as well.

The friction velocity, enacted by boundary layer flow is a crucial factor for interfacial solute exchange (Boudreau \& Guinasso 1982). We conclude that when working with limited-size cores of permeable sediments, including samples of muds with an abundant infauna, the pressure gradients produced by the 


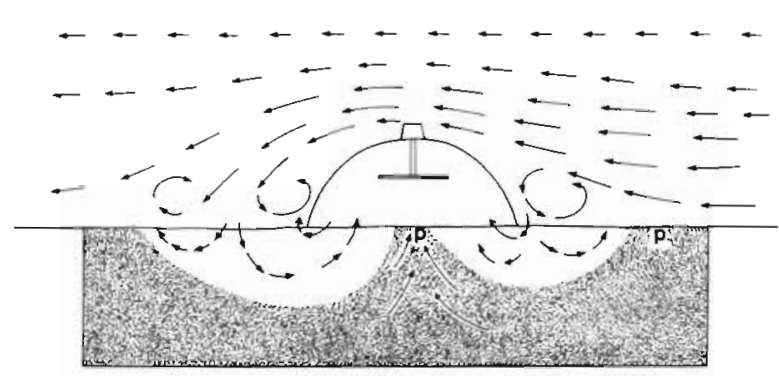

a

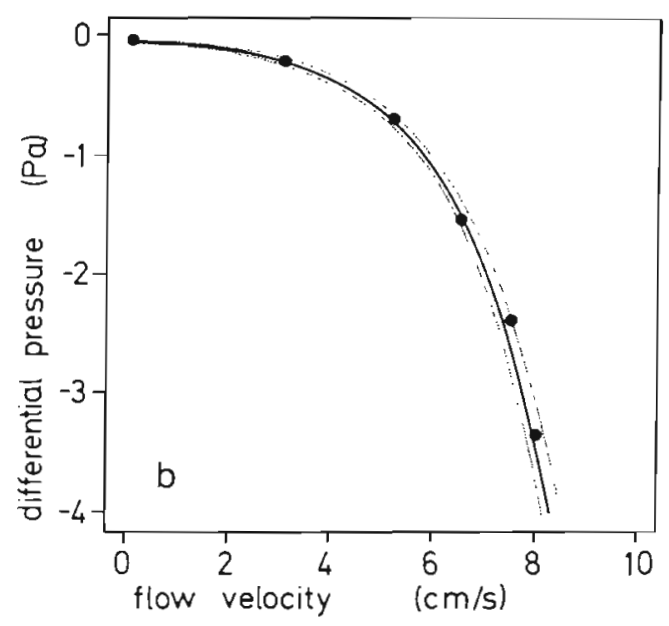

Fig. 8. (a) Centerline transect of the washout pattern produced by a bell jar resting on a large sediment core in a recirculating flume. The bell jar with stirrer bar rotating at $12 \mathrm{rpm}$ was exposed to a flow of $10 \mathrm{~cm} \mathrm{~s}^{-1}$ during the experiment $(24 \mathrm{~h})$. Arrows indicate streamlines of fluid movement. p: Location of pressure ports. Lower pressure was recorded inside the bell. (b) Pressure gradient between chamber water and outside fluid for the tested bell jar exposed to flow of different approach velocities

chamber technique applied, such as circular flow, edge- and wall effects and coupling to environmental boundary-layer flow have to be considered. Deep penetration of the chamber walls into the sediment (minimum $20 \mathrm{~cm}$ for fine sand) eliminates the effect of outside flow. If central stirring cannot be avoided, we found that in the case where the empirical relationship

$$
u .<(0.2 K+2)^{-1}
$$

between friction velocity $u$. (in $\mathrm{cm} \mathrm{s}^{-1}$ ) and permeability $K$ (in Darcy) is observed, the experimental error from using a stirred chamber for solute release is smaller than a factor of 2 (see Fig. 3) compared to the reference core with diffusive release. In accessible areas such as intertidal flats, a possible in situ alternative for unidirectional (tidal) flows, is a rectangular flow chamber producing a 2-dimensional flow of specific recirculation volume over a long sediment core with 'protected' (neutralized) chamber-sediment transition zones, dimensions depending on sediment features and solutes to be measured.

Acknowledgements. This research was supported by a grant from the Deutsche Forschungsgemeinschaft to $\mathrm{M}$. Huettel as part of the Foreign Visitors Exchange Program of the University of South Florida. We thank Prof. W. Noodt (Kiel University, Germany) who helped to realize this project. Stefan Forster, University of Kiel, helped to measure the oxygen profiles. We also appreciate the many helpful comments of W. Bowles and M. Holmes.

\section{LITERATURE CITED}

Aller, R. C. (1982). The effect of macrobenthos on chemical properties of marine sediment and overlaying water. In: McCal], P. L., Tevesz, M. J. S. (eds.) Animal-sediment relations. Plenum Press, New York, p. 53-102

Aller, R. C., Yingst, J. Y (1985). Effects of the marine deposit feeders Heteromastus filiformis (Polychaeta), Macoma baltica (Bivalvia), Tellina texana (Bivalvia) on averaged sedimentary solute transport, reaction rates, and microbial distributions. J. mar. Res. 43: 615-645

Balzer, W. (1986). Forms of phosphorus and its accumulation in coastal sediments of Kieler Bucht. Ophelia 26: 19-37

Berelson, W. M., Hammond, D. E., Smith, K. L. Jr, Jahnke, R. A., Devol, A. H., Hinga, K. R., Rowe, G. T., Sayles, F. (1987). In situ benthic flux measurement devices: bottom lander technology. Mar. Technol. Soc. J. 21(2): 26-32

Berner, R. A. (1976). The benthic boundary layer from the viewpoint of a geochemist. In: McCave, I. N. (ed.) The benthic boundary layer Plenum Press, New York, $p$ $33-55$

Beyer, W. H. (1968), (ed.) Handbook of tables for probability and statistics. CRC Press, Boca Raton, Florida, p. 307-308

Blackburn T H., Henriksen, K. (1983). Nitrogen cycling in different types of sediments from Danish waters. Limnol. Oceanogr. 28: 477-493

Bokuniewicz, H. (1980). Groundwater seepage into Great South Bay, New York. Estuar. coast. mar. Sci. 10: 437-444

Boudreau, B. P., Guinasso, N. L., Jr (1982). The influence of a diffusive sublayer on accretion, dissolution, and diagenesis at the sea floor. In: Fanning, K. A., Manheim, F. T. (eds.) The dynamic environment of the ocean floor. Lexington Books, Toronto, p. 115-145

Bowker, A. H., Liebermann, G. J. (1972). Engineering Statistics. Prentice Hall, Englewood Cliffs, p. 242-251

Boynton, W. R., Kemp, W. M., Osborne, C. G., Kaumeyer, K. R., Jenkins, M. C. (1981). Influence of water circulation rate on in situ measurements of benthic community respiration. Mar. Biol. 65: 185-190

Buchholtz-Ten Brink, M. R., Gust, G., Chavis, D. (1989). Calibration and performance of a stirred benthic chamber. Deep Sea Res. 36: 1083-1101

Chilingar, G. V. (1964). Relationship between porosity, permeability and grain size distribution of sands and sand stones. In: Van Straaten, L. M. J. U. (ed.) Deltaic and shallow marine deposits, I. Elsevier, Amsterdam, p. $71-75$

Chilingarian, G. V., Beeson, C. M., Ershagi, I. (1972). Porosity and permeability. In: Fairbridge, R. W. (ed.) Encyclopedia of earth sciences, Vol. IV. A. Reinhold, New York, p. $464-470$ 
Daniel, W. W. (1978). Applied nonparametric statistics. Houghton Mifflin, Boston.

Dyrssen, D., Hall, P., Westerlund, S. (1984). Benthic chamber chemistry. Inorganic andysis in environmental research and protection. Z. Anal. Chem. 317(3-4): 380-382

Frape, S. K., Paterson, P. J. (1981). Chemistry of pore-water and bottom sediments as indicators of seepage patterns in Perch Lake, Chalk River, Ontario. Limnol. Oceanogr. 26: $500-517$

Gust, G. (1982). Tools for oceanic small scale, high frequency flows: metal clad hot wires. J. Geophys. Res. 87: 447-455

Gust, G. (1988). Skin friction probes for field applications. J. geophys. Res. 93: 14121-14132

Gust, G. (1989). Method and apparatus to generate preciselydefined wall shearing stresses. U.S. Patent No. 4884892

Gust, G., Harrison, J T (1981). Biological pumps at the sediment-water interface: mechanistic evaluation of the alpheid shrimp Alpheus mackayiand its irrigation pattern. Mar. Biol. 64: 71-78

Hallberg, R. O., Bagander, L. E., Engvall, A. G., Schippel, F. A. (1972). Method for studying geochemistry of sediment water interface. Ambio 1(2): 71-72

Harrison, W. D., Musgrave, D., Reeburgh, W. S. (1983). A wave-induced transport process in marine sediments. J. geophys. Res. 88: 7617-7622

Holme, N. A., McIntyre, A. D. (1984). Methods for the study of marine benthos, Blackwell Scientific Publications, Oxford, p. $124-125$

Huettel, M. (1990). Influence of the lugworm Arenicola marina on porewater nutrient profiles of sand flat sediments. Mar. Ecol. Prog. Ser. 62: 241-248

Huettel, M., Gust, G. (1991). Convective porewater flow in permeable sediments affects flux measurements in benthic chambers. ASLO-Aquatic Sciences Meeting Abstracts, Halifax, Canada, June 10-14, 1991. Am. Soc. Limnol. Oceanogr., Lawrence, Abstract vol., p. 44

Huettel, M., Gust, G. (1992). Bioroughness in the millimeter range enhances interfacial solute fluxes in permeable sediments, ASLO-Aquatic Sciences Meeting Abstracts, Santa Fe, New Mexico, February 9-14, 1992. Am. Soc. Limnol. Oceanogr., Lawrence, Abstract vol., p. 97

Hunt, I. A., Joubert, P. N. (1979). Effects of small streamline curvature on turbulent duct flow. J. Fluid Mechan. 91: $633-659$

Kirsten, O. H., Jahnke, R. A. (1985). The Lander recent developments in free vehicle platform design. Oceans's 85 proceedings: ocean engineering and the environment; 1985; Vol. 2. Mar. Tech. Soc., New York, p. 1034-1038

Malan, D. E., McLachlan, A. (1991). In situ benthic oxygen fluxes in a nearshore coastal marine system: a new approach to quantify the effect of wave action. Mar. Ecol. Prog. Ser. 73: 69-81

Opdyke, B. N., Gust G., Ledwell, J. R. (1987). Mass transfer from smooth alabaster surfaces in turbulent flows. Geophys. Res. Letters 14,11.1131-1134

This article was submitted to the editor
Prandtl, L., Tietjens, O. G. (1957). Fundamentals of hydroand aeromechanics. Dover Publications, Inc., New York p. $214-215$

Reise, K. (1985). Tidal flat ecology. Ecological studies 54 Springer Verlag, Berlin, p. 119-136

Rhoads, D. C., Aller, R. C., Goldhaber, M. B. (1977). The influence of colonizing benthos on physical properties and chemical diagenesis of the estuarine seafloor. In: Coull, B C. (ed.) Ecology of marine benthos. University of South Carolina Press, Columbia, p. 113-138

Rhoads, D. C., Boyer, L. F. (1982). The influence of marine benthos on physical properties of sediments: a successional perspective. In: McCall, P. L., Tevesz, M. J. S. (eds.) Animal-Sediment relations. Plenum Press, New York, p $3-52$

Riedl, R. J., Machan, R. (1972). Hydrodynamic patterns in lotic intertidal sands and their bioclimatological implications. Mar. Biol. 13: 179-209

Riedl, R. J., Huang, N., Machan, R. (1972). The subtidal pump a mechanism of interstitial water exchange by wave action Mar. Biol. 13: 210-221

Risk, M. J., Moffat, J. S. (1977). Sedimentological significance of faecal pellets of Macoma baltica in the Minas Basin, Bay of Fundy. J. sedim. Petrol. 47: 1425-1436

Santschi, P. H., Bower, P., Nyffeler, U. P., Azevedo, A., Broecker, W. S. (1983). Estimates of the resistance to chemical transport posed by the deep-sea boundary layer Limnol. Oceanogr. 28: 899-912

Santschi, P. H., Anderson, R. F., Fleischer, M. Q., Bowles, W. (1991). Measurements of diffusive sublayer thickness in the ocean by alabaster dissolution, and their implications for the measurements of benthic fluxes. J geophys. Res. 96(C6): $10641-10657$

Son, J. S., Hanratty, T. J. (1967). Limiting relation for the eddy diffusivity close to a wall. Am. Inst. Chem. Eng. J. 13: $689-707$

Tsvetkova, M. A. (1954). Influence of mineralogic composition of sandy rocks on filtration capacity and oil production. Tr. Inst. Nefti, Akad. Nauk SSSR 3: 3-33

Van der Loeff, M. M. R., Anderson, L. G., Hall, P. O. J., Iverfeldt, A., Josefson, A. B., Sundby, B., Westerlund, S. F. G. (1984). The asphyxiation technique: an approach to distinguishing between molecular diffusion and biologically mediated transport at the sediment-water interface. Limnol. Oceanogr. 29(4): 675-686

Webb, J. E. (1969). Biologically significant properties of submerged marine sands. Proc. R. Soc. London, Ser. B, 174 : $355-402$

Webb, J. E., Theodor, J L. (1968). Irrigation of submerged marine sands through wave action. Nature, Lond. 220: $682-683$

Webb, J. E., Theodor, J. L. (1972). Wave-induced circulation in submerged sands. J. mar biol. Ass. U.K. 52: 903-914

Zeitzschel, B., Davies, J. M. (1978). Benthic growth chambers. Rapp. P.-v. Réun. Cons. int. Explor. Mer 173; 31-42

Manuscript first received: August 26, 1991

Revised version accepted: March 30, 1992 